\title{
Teaching Probability Theory and Forecasting-based Mathematical Statistics to Bachelors of Economics
}

\author{
V.D. Selutin \\ Orel State University \\ Orel, Russian Federation \\ caercauthor@yahoo.com
}

\author{
E.V. Lebedeva \\ Orel State University \\ Orel, Russian Federation \\ caercauthor@yahoo.com
}

\begin{abstract}
The article examines the results of the research study on advisability of using forecasting when teaching probability theory and mathematical statistics to future economists. The timeliness of the study is determined by the fact that the traditional methods of teaching fail to empower students to see any links with their future profession and make use of their probabilistic and statistical knowledge in order to analyse and forecast economic phenomena. Philosophical and hypotheticaldeductive approaches to studying the forecasting potential of the law of large numbers in probability theory make it possible to bring out the opportunities of introducing a number of mathematical notions based on their empirical prototype during the analysis of economic situations. The effectiveness of the proposed method of teaching is assessed according to the achieved level of knowledge and skills that are manifested through students' readiness to apply probabilistic and statistical methods during analysing and forecasting economic phenomena. By means of parameterisation in quantitative terms, the analysis of 120 students' test papers is carried out. The article is of practical value to university instructors in their work, and makes it possible to put a professional economic slant on the process of teaching probability theory and mathematical statistics.
\end{abstract}

Keywords-bachelors; forecasting; probabilistic notions; economic processes.

\section{INTRODUCTION}

Acquisition of probabilistic and statistical methods occupies a crucial role in the process of professional training of economics to undergraduates since every business activity is connected with uncertainty of reaching final results under the influence of random and uncontrollable factors. The analysis of the actual process of teaching probability theory to economics students shows that the majority of them do not understand how it is related to their future profession. Economics undergraduates do not see the need for any mathematical operations and are unable to make use of their probabilistic and statistical knowledge in order to analyse and forecast economic phenomena. For that reason it is urgent to examine different aspects of teaching probability theory and mathematical statistics to economics students on the basis of forecasting.

The major direction of the prior scientific research (A. Plotski [1], G.S. Zhukova [2], O.A. Nikolaeva [3], T.E. Baeva [4], K.N. Lungu [5], V.V. Firsov [6], S.V. Shcherbatych [7], etc.) is realisation of the applied orientation in teaching probability theory, which has been recognised as a principle of teaching stochastics in general. Application of this principle leads to a positive influence on the formation of students' elementary economic thinking (N.V. Tarasova [8]).

However, the implementation of this principle is not fully achieved in the actual pedagogical process. It accounts for the fact that probability theory turns out to be the most challenging branch for students' apprehension in the university course of mathematics.

The analysis of probabilistic and statistical training of future economists demonstrates that the major hindrance to enhancing the applied character of training is its isolation from the topic of managing stable development of economic objects and processes, which is impossible without objective and variable assessment of the future. The process of teaching probability theory and mathematical statistics does not take full advantage of the mechanism of motivation, related to the interest students take in mastering skills of planning and forecasting economic processes.

For example, the questionnaire survey of the second and third year students of Orel State University named after I.S. Turgenev shows that on average $71 \%$ of students surveyed are unable to give more than one example of economic indicators, the value of which is characterised by a random variable and to give the economic interpretation of the main probabilistic and statistical notions.

It is an established fact that at the present stage of development of university mathematical education, there is an apparent contradiction between:

- the necessity of application of probabilistic and statistical methods of forecasting by future economists during the study of major-related subjects and the traditional system of teaching them, which fails to ensure the necessary level of their acquisition after completing the course of mathematics;

- the great forecasting potential of the law of large numbers in probability theory and its insufficient use during professional training of economics undergraduates;

- $\quad$ the opportunities of organising a more effective way of teaching probability theory that makes use of elements of forecasting and the long established traditional formal and logical teaching approaches. 
All the above mentioned facts necessitate the search for new ways of teaching probability theory and mathematical statistics, which take into account the peculiarities of students' future economic activities, in order to increase their cognitive motivation and form thorough basic knowledge that is essential in acquisition of major-related professional series of disciplines.

\section{MATERIALS AND METHODS}

Guided by research carried out by M.A. Gavrilova [9], N.N. Yaremko [10], S.N. Dvoryatkin [11], U.S. Antipova [12], V.F. Gabdulchakov [13], a new method of teaching students probability theory on the basis of forecasting is devised. The starting point of its theoretical foundation is the fact that forecasting plays an important role in professional activity of bachelors of economics. Consequently, introduction of forecasting into the methodological system of teaching probability theory and mathematical statistics to future economists will allow increasing significantly the quality of basic probabilistic notions acquisition as well as favour formation and actualisation of certain significant professionrelated skills of identifying economic trends.

Notions of probabilistic theory studied according to the traditional method (V.E. Gmurman [14], A.N. Frolov [15], N.Sh.Kremer [16]) do not conform with the idea of forecasting. Their study should be based on statistical conceptions that constitute the empirical foundation of these notions. It is necessary to begin with the topic "Initial processing of experimental results" that will promote formation of the first statistical conceptions among students and allow to develop skills necessary for carrying out primary stages of forecasting.

In addition, dealing with collected for forecasting purposes empirical data and acquaintance with actual experimental demonstrations of the law of large numbers favour better understanding of such notions as statistical stability in the world of randomness and orderliness of chance factors. As a result, favourable conditions for a natural transition to some probabilistic notions from their statistical forerunners in forecasting terminology are formed.

The distinctions between the devised course in probability theory and mathematical statistics and the traditional course consist in the following:

1. The study of the basic probabilistic notions and theorems is grounded on the statistical conceptions that constitute their empirical foundation. Presentation of the theoretical aspects based on actual statistical data and accompanied by compilation and analysis of tables and diagrams, which are a result of data grouping, is aimed at making students realise the probabilistic character of economic phenomena and the major differences between the statistical and deterministic research approaches. Tabulated and diagrammed statistical data prompt attempts to extrapolate the observed properties of elements of a sample to the general population and forecast economic indicators evolution.

For example, the following situation is offered to students. The owner of the firm is convinced that he has failed to achieve better financial results due to irregularity in monthly components delivery despite the fact that the supplier has fully complied with his obligations over the year. The distribution of deliveries by month is shown in Figure 1.

What volume of deliveries can the owner of the firm expect in the period ahead? In the diagram choose the most probable final segment among the three suggested variants.

Such types of tasks favour formation of elementary statistical conceptions among students and develop skills necessary for carrying out primary stages of forecasting. However, the experiment made it clear that solving elementary forecasting problems only during practical sessions is not enough for formation of systematic understanding of correlation between statistical and probabilistic notions under study. Thus, it is deemed necessary to introduce probabilistic notions in conjunction with statistical ones.

It is found out that dealing with collected for forecasting purposes empirical data and acquaintance with actual experimental demonstrations of the law of large numbers favour better understanding of statistical stability in the world of randomness and orderliness of chance factors. As a result favourable conditions for a natural transition to some probabilistic notions directly from their statistical forerunners are formed.

2. Introduction of basic probabilistic notions (probability, mathematical expectation, plot of the cumulative distribution function, plot of the density function, etc.) rests upon "theoretically expected" mathematical abstractions in the course of mental forecasting provided there is an unlimited increase in the number of experiments:

- probability of an event as a result of forecasting frequency value;

- mathematical expectation of a random variable as a result of the sample mean forecasting;

- plot of the cumulative distribution function of random variable probabilities as a result of forecasting cumulative frequency polygons patterns;

- plot of the probability density function as a forecasting histogram pattern;

- regression line as a result of forecasting the broken line of mean values (empirical line of regression);

correlation coefficient of two random variables as a result of forecasting of the empirical correlation coefficient of two attributes.

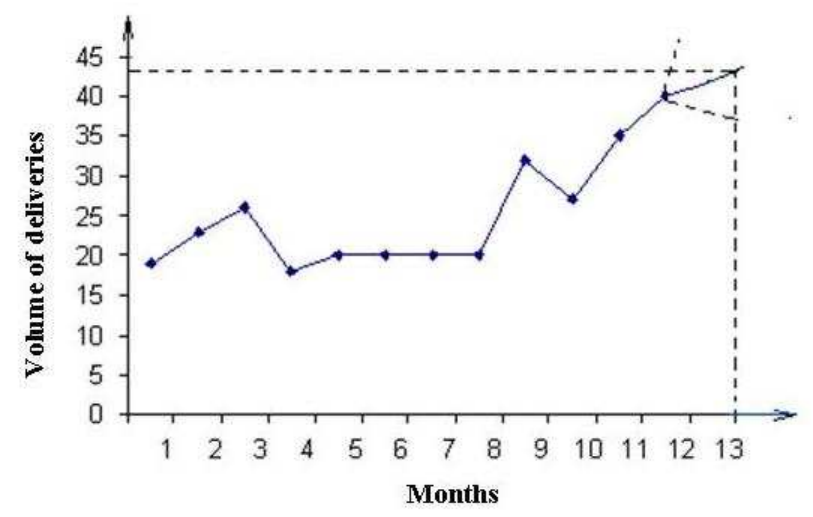

Fig. 1. Distribution of deliveries by month 
Mental extrapolation of the course of the actual experiment, provided there is any number of observations to be made, gives students the idea that they can try and "forecast" results. Owing to it, a transition to a probabilistic notion from its statistical forerunner takes place. Analysis of correlation between the probabilistic model and its empirical prototype after the probabilistic notion was defined makes it possible to "forecast" results of future experiments.

This approach to introduction of basic probabilistic notions presupposes looking at motivating examples, the analysis of which will ensure a transition from actual to abstract, and only then, formal construct.

For example, study the information about the time that determines the duration of the house construction investment project (Figure 2). What is the probability of completing the investment project in less than 12 months?

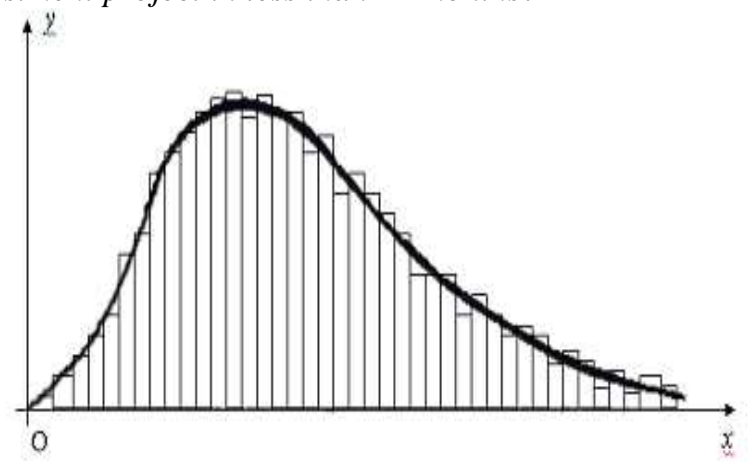

Fig. 2. Histogram and plot of probability density function

Having plotted a histogram, students conclude that the estimated probability of completing the investment project in less than 12 months is $55 \%$. Moreover, they forecast the pattern of the histogram under the conditions of mass statistical investigation. It creates favourable conditions to deduce a stability property of a histogram: with the increase in the number of experiments and reduction in grouping intervals the continuous attribute histogram pattern approaches (with rare exceptions) a certain line. This theoretically expected line is referred by the students as the plot of the probability density function $y=f(x)$ (Figure 2).

Consolidation of the covered probabilistic notions and methods is done by means of mathematical modelling of economic situations of prognostic character. This process involves all stages of solving applied problems: from setting goals formulated in economic forecasting terminology through the choice of probabilistic and statistical ways of achieving them to obtaining the mathematical result and its interpretation in order to produce a forecast.

For example, in order to improve students' knowledge of the law of total probability and Bayes' theorem students are offered the following data (Table 1), received during the population survey on employment issues. Their task is to make a forecast about the educational level of people, who can lose their employment in the near future, if under the conditions of the problem there are 82 men and 168 women among the unemployed.
TABLE 1. DISTRIBUTION OF THE UNEMPLOYED POPULATION ACCORDING TO THEIR EDUCATIONAL LEVEL

\begin{tabular}{|l|c|c|}
\hline \multicolumn{1}{|c|}{ Education } & Men & Women \\
\hline Higher education & 0.146 & 0.304 \\
\hline Vocational education & 0.390 & 0.226 \\
\hline Secondary education & 0.317 & 0.351 \\
\hline Have no education & 0.147 & 0.119 \\
\hline
\end{tabular}

Similarly, in order to consolidate the understanding of the notion "probability of the event", students examine the information about the distribution of male and female economically active population, both employed and unemployed, according to their educational level. Its probabilistic interpretation allows considering the relative frequencies as estimates of conditional probabilities of corresponding events occurrence.

For example, if 0.304 is a fraction of women who have higher education among the unemployed women, then 0.3 is the probability estimate of an unemployed person having a university degree under the condition that it is a woman.

Using the formula of total probability students make calculations that allow of concluding that the probability of becoming unemployed among people with secondary education in comparison with people who have higher education is 1.3 times higher $(0.34$ and 0.25 are the calculated values of total probability of the event "Unemployed is the person with secondary education" and the event "Unemployed is the person with higher education" respectively).

Such information is interesting both from sociopsychological and economic points of view because it exerts a positive influence on different population groups stimulating them to raise their educational level. In reality the population employment is influenced not only by gender and educational level, but also by age, record of service and other factors.

Experimental work carried out within the framework of this research study confirmed that teaching probability theory and mathematical statistics to bachelors of economics on the basis of forecasting improves students' skills of solving standard problems and of using mathematical methods to analyse and forecast economic phenomena (Table 2).

TABLE 2. TEST RESULTS OF THE EXPERIMENTAL AND CONTROL GROUPS

\begin{tabular}{|c|c|c|}
\hline $\begin{array}{c}\text { Number of tasks } \\
\text { solved }\end{array}$ & \multicolumn{2}{|c|}{$\begin{array}{c}\text { Number of students who coped with } \\
\text { the tasks }\end{array}$} \\
\cline { 2 - 3 } & $\begin{array}{c}\text { Experimental } \\
\text { group (EG) }\end{array}$ & $\begin{array}{c}\text { Control group } \\
\text { (CG) }\end{array}$ \\
\hline 4 & $14(23.7 \%)$ & $4(6.6 \%)$ \\
\hline 3 & $16(27.1 \%)$ & $9(14.7 \%)$ \\
\hline 2 & $15(25.4 \%)$ & $29(47.5 \%)$ \\
\hline 1 & $10(17 \%)$ & $17(27.9 \%)$ \\
\hline 0 & $4(6.8 \%)$ & $2(3.3 \%)$ \\
\hline
\end{tabular}

\section{RESULTS}

As a result of the current research study, a new idea about organising the process of teaching probability theory and mathematical statistics based on the elements of forecasting to economics students is proposed and devised. The potential and advisability of using forecasting in probabilistic and statistical training of future economists during their course of study at the university are substantiated. The basic probability- 
theoretical notions genetically connected with the idea of forecasting (probability of the event, mathematical expectation of random variable, plots of the cumulative distribution function and the probability density function, regression line, correlation coefficient) are singled out.

The specific character of means of interaction among probabilistic, statistical and forecasting aspects in solving mathematical problems is brought to light: formulating tasks on forecasting in mathematical terms; focusing mathematical calculations on obtaining a model that adequately reproduces the forecast situation; mathematical result interpretation in terms of the original situation along with a forecast object estimate; identification of the alternative ways of development and evaluation of consequences of the decisions made; accumulation of information to substantiate the choice of solution; put forward hypotheses in the form of statistical forecasts.

The probability theory and mathematical statistics course content is specified and directed toward professional training of first-rate economists. Besides, the sequence of studying the basic notions in conjunction with a wide use of forecasting is determined. The method of teaching probability theory and mathematical statistics based on forecasting is devised and its effectiveness is proved.

A variant of introducing basic probabilistic notions seen as mathematical abstractions of the result of their empirical prototypes forecast is proposed.

\section{DISCUSSION}

The research study indicates that economic forecasting can be used as a way to implement the applied orientation in teaching probability theory and mathematical statistics because its functions are directly correlated with the basic stages of practical application of mathematics: 1) goal setting under conditions of forecasting; 2) choice of a mathematical model of achieving it and obtaining a probabilistic and statistical result; 3) making use of the received mathematical result to produce a forecast.

In this connection, the probability theory and the statistical mathematics course content component of should be adjusted in accordance with the specific character of students' professional training regarding economic trends detection. The sequence of teaching the basic notions of probability theory to bachelors of economics presupposes preliminary examination of their empirical prototypes in situations of forecasting and favours formation of students' elementary skills necessary for economic trends identification.

Studying probability-theoretical notions on the basis of forecasting enables students to discover them for themselves within the framework of examining experimental demonstrations of the law of large numbers as "theoretically expected" mathematical abstractions during mental forecasting of empirical prototypes. It is deemed reasonable to consolidate knowledge of the covered probabilistic notions and methods by means of mathematical modelling of economic situations of prognostic character.

The devised method of teaching students is conducive to their readiness to apply mathematical knowledge during the study of professional disciplines and formation of significant profession-related skills of identifying economic trends since it includes: a) formation of elementary forecasting skills necessary for understanding the law of stability of mass random phenomena by means of descriptive statistics; b) introduction of basic probability-theoretical notions under conditions of forecasting during examination of experimental demonstrations of the law of large numbers; c) consolidation of the covered notions and methods during production of economic trends.

\section{CONCLUSION}

Thus, a scientifically substantiated thesis about the possibility and advisability of teaching probability theory and mathematical statistics on the basis of forecasting expands boundaries of implementing professional economic orientation of the educational process. Application of the devised method by university instructors during lectures and practical sessions will allow one not only to increase the level of knowledge and improve skills of solving mathematical problems, but also to help students to master techniques of probabilistic forecasting for deeper understanding and active application of quantitative analysis methods of economic processes when studying majorrelated professional subjects and organising students' scientific research.

\section{References}

[1] A. Plotski, "Stochastic tasks and applied orientation in teaching mathematics," Mathematics in school, 3, pp. 69-71, 1991.

[2] G. Zkukova, and E. Romanova, "Analysis of main trends in professional applied mathematical training of future specialists in economics at the university," Societal politics and sociology, 3-2(95), pp. 23-33, 2013.

[3] O. Nikolaeva, "Professionally oriented tasks on probability theory for economics major students," Didactics of Mathematics: Problems and Research, 40, pp.135-140, 2013.

[4] T. Baeva, and K. Sankina,"Applied character of probability theory as means of forming economic thinking," Agrarian science, creativity, growth, pp. 12-16, 2015.

[5] K. Lungu, "Professional applied orientation of teaching mathematics to economics major students and its realisation," Development of science and education. The problems of teaching in higher education, pp. 99$105,2011$.

[6] V. Firsov, "On applied orientation of mathematics course," Mathematics in school, 6, pp. 2-13, 2006.

[7] S. Shcherbatykh, and A. Rogacheva, "Upper-Formers' Stochastic Culture: Essential Features, Formation Technology," Indian Journal of Science and Technology, 9(19), pp. 250-257, 2016.

[8] N. Tarasova, "Method of giving interactive lessons on probability theory at the economic university," Pedagogy and life, pp. 25-28, 2013.

[9] M. Gavrilova, N. Yaremko, and D. Dmitriyev, "Formation of criteriacorrectness mathematical competence," European Journal of Research and Reflection in Educational Sciences, 1(3), pp. 61, 2015.

[10] N. Yaremko, "The Criterion-correctness mathematician competence formation on the base of theory of pedagogical interaction systems functioning and development Science and Education," Materials of the V International Research and Practice Conference, vol. II. Munich, Germany, pp. 153-157, 2014.

[11] S. Dvoryatkina, "A structural model development of the probabilistic style of students' thinking in learning mathematics on the basis of the dialogue of cultures," European Social Science Journal, 6(22), pp. 83$92,2012$. 
[12] Yu. Antipova, "Role of applied orientation in teaching mathematics," Science of the 21 st century: the experience of the past - vzglayd into the future, pp. 3-6, 2015.

[13] V. Gabdulchakov, A. Kusainov, and A. Kalimullin, "Education reform at the science university and the new strategy for training science teachers," International Journal of Environmental and Science Education, 3(11), pp. 163-172, 2016.

[14] V. Gmurman, "Probability theory and mathematical statistics," Moscow: Urite, 2014.

[15] A. Frolov, "Limit theorems for small deviation probabilities of some iterated Stochastic processes," Journal of Mathematical Sciences, 6(188), pp. 758-760, 2013

[16] N. Kremer, "Probability theory and mathematical statistics," Moscow: UNITI-DANA, 2012. 